\title{
Focused Ultrasound Therapy of the Prostate with MR Guidance
}

\author{
Alessandro Napoli · Gaia Cartocci • \\ Fabrizio Boni - Maurizio Del Monte • \\ Vincenzo Noce $\cdot$ Michele Anzidei $\cdot$ Carlo Catalano
}

Published online: 22 February 2013

(C) Springer Science+Business Media New York 2013

\begin{abstract}
Prostate cancer (PC) is one of the most common cancers in the male population worldwide. Focal therapy for $\mathrm{PC}$ is now considered an emerging alternative to active surveillance for the management of low-risk PC, with the overall aim of treating only areas of cancer, minimizing lifetime morbidity without compromising life expectancy. One option within focal therapy, high intensity focused ultrasound (HIFU), represents an innovative technique that may selectively ablate known the disease while preserving existing functions. In the last 10 years, the feasibility and the safety of US guided HIFU has been tested in a growing number of clinical studies. More recently, magnetic resonance imaging was combined with HIFU principle and was presented as a novel technique for focal ablation of PC. In this review we introduce the technology of Magnetic Resonance guided Focused
\end{abstract}

\author{
A. Napoli $(\bowtie) \cdot$ G. Cartocci · F. Boni - M. Del Monte · \\ V. Noce $\cdot$ M. Anzidei - C. Catalano \\ Department of Radiology, Oncology and Anatomic Pathology, \\ Policlinico Umberto I, Sapienza University of Rome, Viale \\ Regina Elena, 324, 00161 Rome, Italy \\ e-mail: alessandro.napoli@uniroma1.it \\ G. Cartocci \\ e-mail: gaia.cartocci@gmail.com \\ F. Boni \\ e-mail: fabrizioboni00@gmail.com \\ M. Del Monte \\ e-mail: delmonte_maurizio@libero.it \\ V. Noce \\ e-mail: vinc.noce@hotmail.it \\ M. Anzidei \\ e-mail: michele.anzidei@gmail.com \\ C. Catalano \\ e-mail: carlo.catalano@uniroma1.it
}

Ultrasound (MRgFUS) and the current status of clinical applications in the therapy of PC.

Keywords Prostate cancer - MR guided focused ultrasound · MRgFUS · High intensity focused ultrasound · HIFU · Focal therapy

\section{Introduction}

Prostate cancer (PC) is recognized as one of the most common cancer in males all over the world, with recent statistics reporting an incidence of $30 \%$ in the United States over the last year [1]. The introduction of prostatespecific antigen (PSA) testing has nearly doubled the lifetime risk of receiving a diagnosis of $\mathrm{PC}$ and has led to a decrease in cancer mortality [2]. D' Amico et al. developed the concept of risk stratification, which provides for the classification of men into low, intermediate, and high-risk pretreatment groups using a combination of clinical data: PSA, Gleason sum, and clinical stage (Table 1). Currently, the treatment of low risk PC remains controversial [3]; approximately $29 \%$ of patient are referred to active surveillance, $33 \%$ to radiotherapy and $39 \%$ to radical prostatectomy (RP) [4]. In most of the cases, RP is curative and in several centers represents the first-line treatment choice, even if associated with higher morbidity as compared to other therapeutic options [5]. Recently, treatment approaches that do not involve an intervention, i.e. active surveillance, or percutaneous techniques that preserve existing functions and selectively ablate target lesions in prostate glands, are significantly growing in popularity and clinical acceptance [6 $6^{\bullet}$. HIFU features high energy ultrasound focused to ablate target tissue thermally by raising the local temperature over $60{ }^{\circ} \mathrm{C}$, leading to coagulative 
Table 1 The classification developed by D'Amico and colleagues is one of the most widely used in clinical practice and is a good starting point for risk assessment

\begin{tabular}{|c|c|c|c|}
\hline \multicolumn{4}{|c|}{ Risk classification (D'Amico) } \\
\hline & Stage & PSA (ng/ml) & Gleason \\
\hline Low risk & $\mathrm{T} 1-2 \mathrm{a}$ & $\leq 10$ & $\leq 6$ \\
\hline Intermediate risk & $\mathrm{T} 2 \mathrm{~b}$ & $>10$ and $\leq 20$ & 7 \\
\hline High risk & $\mathrm{T} 2 \mathrm{c}-3 \mathrm{a}$ & $>20$ & $\geq 8$ \\
\hline
\end{tabular}

This system uses PSA level, Gleason grade, and T stage to group men as low, intermediate, or high-risk

necrosis [7]. The first HIFU ablations of PC were performed under conventional ultrasound (US) guidance [810] more than 15 years ago. Currently, HIFU has been presented as an alternative therapeutic option for localized PC in the Guidelines of the American Urological Association (AUA) in 2007 [11] and of the European Association of Urology (EAU) in 2008 [3]. Recently, magnetic resonance imaging (MRI) has been proposed as a guidance and monitoring modality (Magnetic Resonance guided Focused Ultrasound Surgery-MRgFUS) [12], introducing some relevant advantages over other imaging options. Of particular note, the advantages include superior anatomical resolution and tumor detection, thanks to dynamic contrast enhanced imaging (DCE-MRI), spectroscopy, diffusion weighted imaging (DWI) [13-15], and fast thermal mapping with the proton-frequency shift (PRF) method, which controls the rising temperature and confirms ablation in real-time during the treatment [16]. MRI can be performed also as a post-treatment monitoring technique for immediate evaluation of procedure efficacy [17, 18]. First results of prostate MRgFUS obtained with canine models appear promising $[19,20]$ but, at present, the current literature reports just occasional case descriptions of MRgFUS ablations of prostatic cancer in humans [21, 22], hence its feasibility, safety, and efficacy are still under investigation. The purpose of this review is to describe the MRgFUS technique with particular regard to the technical details of prostate ablation, to present preliminary clinical results in the treatment of localized low-risk PC, and to evaluate and compare consolidated clinical data available in literature regarding HIFU ablation of the prostate.

\section{Focal Therapy}

Considering the potential morbidity of radical therapy (RP, external beam radiation therapy), a number of criticisms have been raised arguing that PC is being overtreated; these arguments have led to increased interest in alternative strategies and treatment options [6•,23]. Focal therapy lies between active surveillance and radical therapy, with a goal of identifying the specific area of the prostate affected by the tumor and selectively ablating it, sparing uninvolved tissue $[24,25]$. This concept still takes the multifocal nature of PC into account, but it is based on the assumption that only the index lesion is eventually responsible for severe consequences for a patient's life; the remaining lesions are just overtreated as they could be successfully managed conservatively. As a consequence, a variety of focal therapy have been proposed and are under clinical evaluation (Laser, CryoAblation etc.). HIFU therapy is emerging as an alternative to active surveillance for the non-invasive management of low-risk of PC [9]. Moreover, the conservative approach sparing the neurovascular bundle leads to a low rate of genitourinary side-effects.

\section{Focused Ultrasound Principles}

Acoustic energy for HIFU is generated by piezoelectric transducers operating at frequency values between 200 $\mathrm{kHz}$ and $4 \mathrm{MHz}$ with an intensity in the focal region in the order of $100-10,000 \mathrm{~W} / \mathrm{cm}^{2}$. Advanced transducers are composed of multiple elements that allow greater control of the acoustic field; each element or element group is fed by separate electrical RF-signals with defined phase shifts and amplitudes, allowing both electrical beam forming and steering of the ultrasound focus, which are necessary to target different locations. These transducers also increase the focal volume per sonication and eliminate the need of mechanical motion with the capability to steer the focal point electronically [26]. By propagation through the tissue, the ultrasound waves are absorbed and the acoustic energy is transformed to heat inside the focal zone: in fact, at this site, the high energy density can increase tissue temperature to $60{ }^{\circ} \mathrm{C}$ or more [27]. If these temperature ranges are maintained for an adequate amount of time (usually more than 10-15 s, depending on both HIFU beam and tissue characteristics), the heat can induce protein coagulation [28], with the surrounding tissue remaining unaffected due to the circumscribed focal spot and low acoustic energy dispersion outside of it (Fig. 1).

\section{Hifu Experiences Using us Guidance}

Over the last 10 years, more than 15,000 patients with PC have been treated with HIFU in Europe, USA and Asia. Two US guided HIFU systems are commercially available: The Ablatherm (EDAP Technomed, Lyon, France) and the Sonablate 500 (Focus Surgery, Indianapolis, IN, USA). The treatment is performed using endorectal probes containing 
Fig. 1 Time-temperature relationship allows to calculate a "thermal dose" for cancer treatment and to estimate biological effect of clinical hyperthermia on tissue, depending on their properties. From [41], with permission

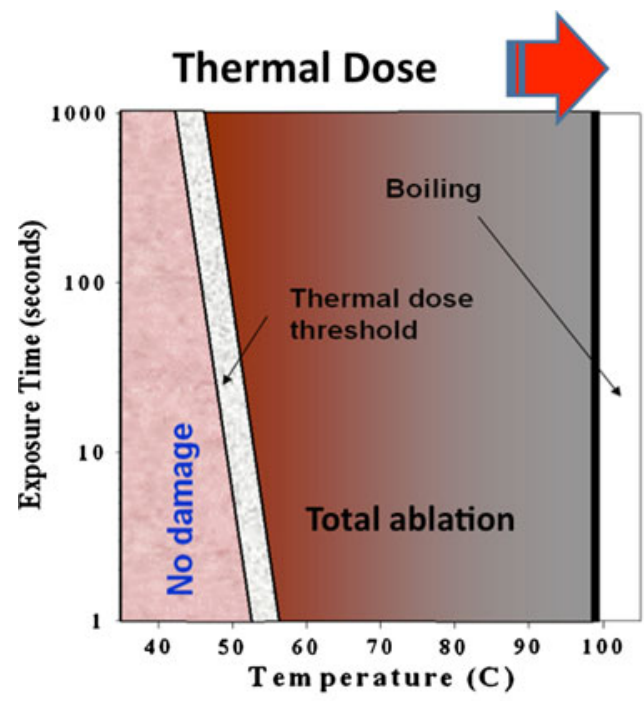

Tissue ablation

$43^{\circ} \mathrm{C}-4$ hours

$54^{\circ} \mathrm{C}-3$ second

$57^{\circ} \mathrm{C}-1$ second
Tissue Temperature

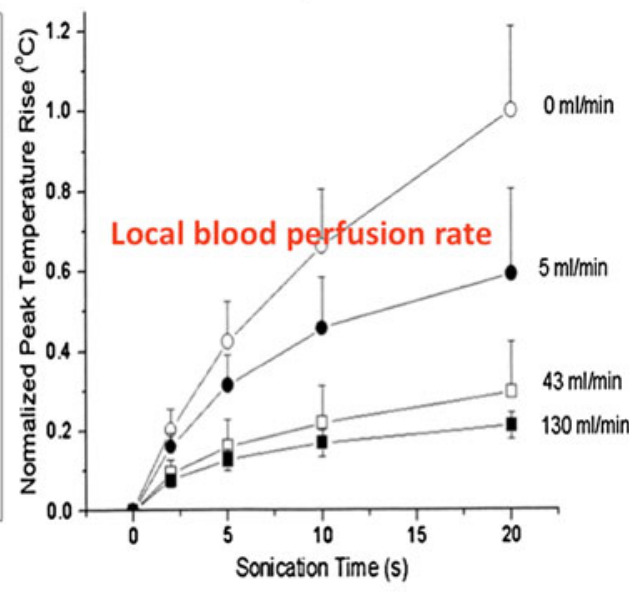

Tissue Variability

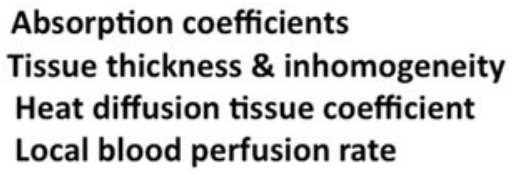

the HIFU transducer and a diagnostic ultrasound imager for treatment planning. The first HIFU experience for the treatment of PC was reported in 1995 by Mathersbacher et al. These initial clinical results helped to clarify the effect of focal length on HIFU lesion volume, the impact of tissue composition, and the feasibility and safety of US guided HIFU for prostate ablation. From 2000 to 2012, Warmuth et al. [29] identified 20 prospective case series, each of which treated between 58 and 517 patients. In total, in the past decade, 3,018 patients were treated with HIFU: $93 \%$ for primary therapy and $7 \%$ for salvage HIFU. For all procedures, the biochemical disease-free survival rate at 1 , 5 , and 7 years, respectively, was 78-84, 45-84, and $69 \%$. The negative biopsy rate was $86 \%$ at 3 and $80 \%$ at 15 months. Overall survival rates and PC-specific survival rates were 90 and $100 \%$ at 5 years and 83 and $98 \%$ at 8 years, respectively. Adverse events were represented by urinary tract lesions (1-58\%), sexual activity alterations (1-77\%), rectal lesions (0-15\%) and local pain (1-6\%). More recently, with the intent to reduce side effects related to HIFU treatment, some authors introduced the concept of focal HIFU for PC as a potential method of achieving tumor control with a lesser degree of morbidity [8, 30]. In particular, a 2012 study published in Lancet Oncology endorsed the clinical application of HIFU in the focal therapy of PC. In this study, Ahmed and colleagues standardized the process of focal therapy by setting three cornerstone principles for prostate ablation: ablation of a maximum of $60 \%$ of gland volume; edge of the ablation zone to be at least $10 \mathrm{~mm}$ from a neurovascular bundle or
$5 \mathrm{~mm}$ if disease was bilateral; untreated areas to be free from any histological evidence of PC. The study population included 42 men. Of them, $89 \%$ had erections sufficient for penetration 12 months after focal therapy, and all patients with no baseline urinary incontinence were leak-free and pad-free by 9 months. Additionally, no histological evidence of cancer was identified in $77 \%$ of men at biopsies six months after treatment [31••]. There are, however, some relevant limits in the assessment of treatment efficacy that are related to the intrinsic technical nature of conventional US guidance. In fact, as for the last cited study, imaging work up for focal therapy has always managed with MRI; it is therefore possible to speculate that the poorer oncological control of true focal therapy (as compared to whole gland approach) by HIFU is mostly related to the suboptimal imaging guidance (compared to MRI). For this reason, the introduction of MR guided focused ultrasound could represent a significant innovation among the clinical options for the focal therapy of PC, combining the ablative therapy of HIFU and the imaging guidance of MRI for precise treatment planning and monitoring.

\section{Magnetic Resonance Focused Ultrasound: Mrgfus}

At present, MRI is one of the most accurate techniques used to investigate the local anatomy of the male pelvis in detail and is particularly helpful for localization and staging of PC. Traditional prostate MRI has been based on morphologic imaging with standard T1-weighted and 
T2-weighted sequences, which has limited accuracy. Recent advances including DWI, $1 \mathrm{H}$-spectroscopic imaging, and perfusion imaging allow extension of the obtainable information beyond anatomic assessment [13]. All of these techniques have shown their potential value in distinguishing malignant PC from benign PC, however, none of them used alone is capable of optimally characterizing tumors in the prostate [32]. For guiding and monitoring HIFU ablation, MRI could be considered more accurate than US as it offers clear advantages: first, it provides highresolution imaging in any orientation for planning treatment and evaluating relative effects thanks to soft tissue contrast; second, MRI is the only currently available technique with proven capabilities to create quantitative temperature maps. MR based thermal imaging provides a means to ensure that the proper ultrasound exposures are being applied for a safe and effective ablation on the target volume without effects to surrounding tissues [18, 33].

Magnetic resonance PRF thermometry allows noninvasive temperature monitoring during ul- trasound thermal ablation. This method uses the temperature dependence of the PRF, which can be determined from the phase in gradient echo images [34]. In order to provide volumetric and rapid thermometry, the acquisition sequences are multislice, gradient-recalled, single-shot, echo-planar imaging (EPI). Moreover, developments in MR imaging hardware and software (3-T vs 1.5-T imaging) continue to improve spatial and temporal resolution and the signal-to-noise ra-tio of MR imaging examinations [14]. MRgFUS has been used extensively in the successful treatment of uterine fibroids and has been shown to be an effective treatment option for the palliative ablation of painful bone metastases [35]. In consideration of its technical features, MRgFUS has been also successfully tested in small patients groups for the treatment of breast, prostate, pancreas, and liver tumors, as well as for spinal rizothomy in subjects with refractory non-discal low back pain and for functional neurosurgery [36]. In our institution, all treatments are performed on a 3T scanner (Discovery 750 General Electric) with dedicated MRgFUS device (ExAblate 2100, InSightec, Haifa, Israel). At present, in our unit, five patients with unifocal, biopsy proven PC, indicated to RP, underwent MRgFUS prior to surgery in a phase I, controlled trial; target lesions were identified with Turbo Spin Echo T2-weighted, DCE T1-weighted, and DWI sequences and served as planning for subsequent MRgFUS ablation. An endorectal probe featuring a phased-array focused ultrasound transducer was positioned for lesion ablation under MRI guidance. The tissue temperature and accumulation of thermal damage in the target zone was monitored during the procedure by MRI thermometry. The procedure was performed during spinal anesthesia without complications, and no pathological enhancement was demonstrated in a DCE MRI performed immediately after treatment. All patients subsequently underwent radical retropubic prostatectomy without significant surgical difficulties in relation to the previous MRgFUS treatment. A histopathology report showed an extensive coagulative necrosis with no residual tumor in the ablated area, surrounded by healthy tissue with inflammatory changes [37].

\section{Treatment Protocol}

Patients may be subjected to peripheral block by spinal anesthesia. A urinary catheter should be positioned to ensure urine flow during the procedure, which is needed mainly to reduce prostate movement due to bladder filling. Patients are positioned on the treatment table and an endorectal coil is inserted into the rectum after lubrication. The coil balloon is then filled with $10 \mathrm{cc}$ of ultrasound gel to eliminate possible air bubbles. The treating physicians identify the focus/i to be targeted, drawing the contours of the target area (ROT-region of treatment) on morphological images from multiparameric MRI (including T2-weighted, DCE and DWI all acquired at treatment stage), as well as safety regions that should be spared, like the rectal wall, urethral sphincter, neurovascular bundles, and the bladder wall. A dedicated treatment-planning software automatically generates a treatment program, including type and number of sonications required to ablate specific regions. A central location of the ROT is then sonicated with an acoustic energy transmission at subtherapeutic power level, with the intent to test and to confirm adequate energy deployment and temperature increase in the target area. When targeting has been confirmed, energy levels are thereafter adjusted to achieve tissue coagulation, with sonication continuing until the entire target volume has been ablated; continuous energy delivery is ensured by high density elements (990) in the transducer with electronic steering for focus movement along predetermined margins. Real time monitoring allows continuous control of temperature variations also in critical structures (especially rectal wall), giving the operator the full control of the treatment and the ability to stop any time the procedure. After treatment completion, the ablated region is re-evaluated with T2-weighted and T1-weighted contrast enhanced sequences in order to assess lesion necrosis (Fig. 2) and immediately identify possible side effects on surrounding tissues.

\section{Hifu as a Salvage Therapy in Local PC Recurrence}

Definitive local therapy after external beam radiation therapy (RT) failure is indicated in patients with local 
Fig. 2 Gleason $6(3+3)$ tumor of the left prostatic lobe in a 63 years old patient is detected as (a) a homogeneus focus of low signal intensity on a transverseT2-weighted MR images. Before starting MRgFUS treatment a planning software generates a treatment program, including type and number of sonication required to ablate target area $(\mathbf{b})$; real time monitoring allows continuous control of temperature variations while sonications are performed under MR guidance (c). Axial T1-weighted Gradient Echo images after injection of gadolinium, performed after MRgFUS treatment shows tissue necrosis (d) in the area of ablation
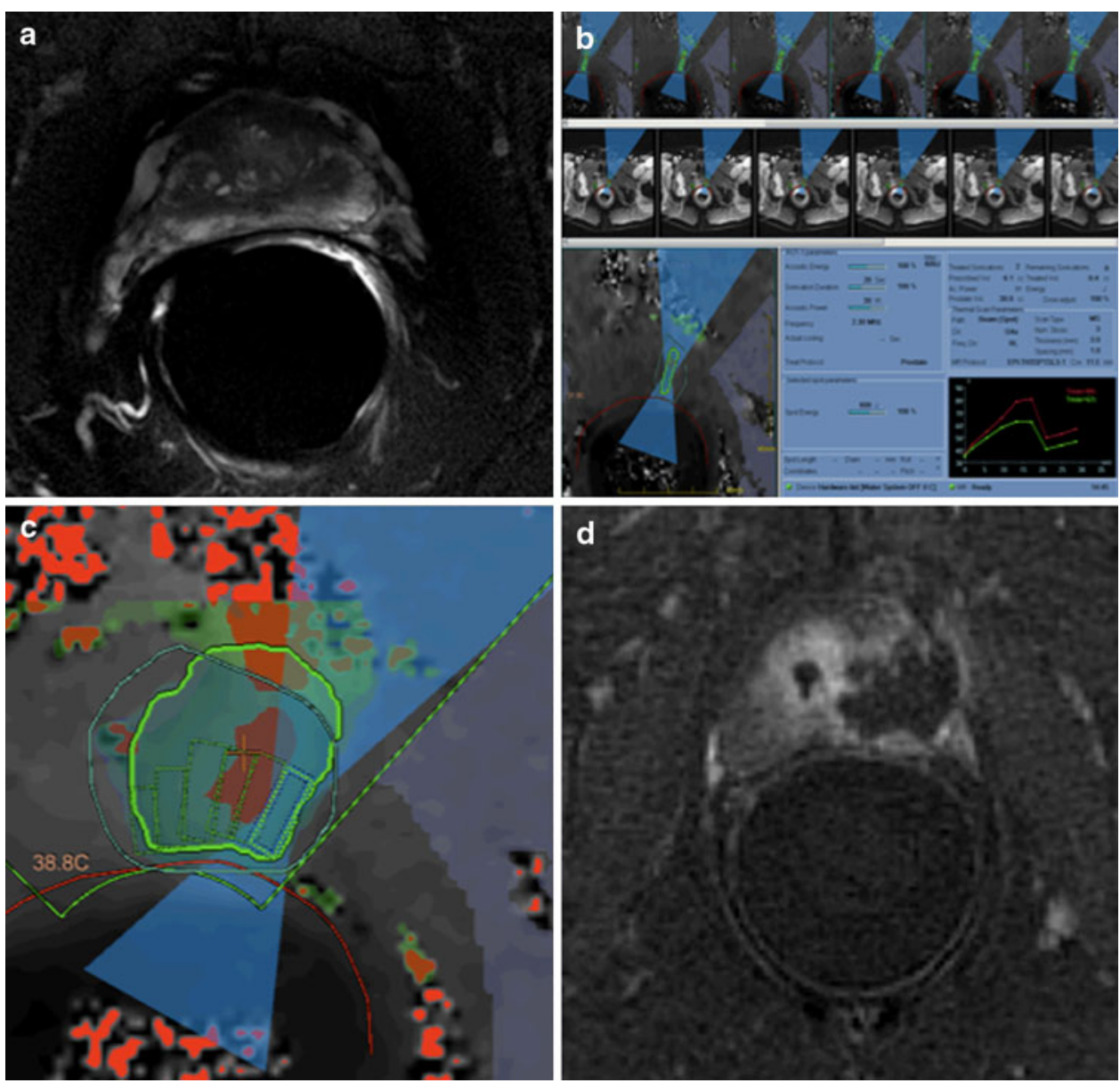

recurrence without metastasis evidence; biochemical failure in these patients can occur in $\sim 10-30 \%$ of the population. At present, there is no widely accepted consensus regarding post-RT patient evaluation; experience with HIFU treatment with US guidance is still limited and shows that complications after salvage HIFU are much higher than after primary HIFU [38, 39]. MRgFUS has not been used yet - to the best of our knowledge-in the management of local recurrence of PC; in our unit we only attempted to treat one patient after RP, but in absence of the prostate gland, the distance between the transducer and the rectal wall is increased thus exposing the rectum to possible thermal damage. Moreover, fibrous tissue secondary to surgical approach is avidly accumulating ultrasound energy as it happens in scars of the skin that are more prone to skin burn.

In fact, these patients have a significant risk of genitourinary and bowel complications as the viability of surrounding tissues may have been compromised by previous surgery or radiation [40].

Currently, we would limit the MRgFUS treatment of prostate gland to primary cancer and would recommend to approach local recurrence with caution and use it when the system will solve minor technical issues.

\section{Conclusions}

Focal therapy is an attractive alternative option in the management of low risk PC.

The currently accepted curative treatment approaches for localized PC depend on patient and tumor factors and account for RP, Radiotherapy/Brachytherapy, and more recently, HIFU. The decision to use HIFU rather than surgery is often made on the basis of patient factors. The increased popularity of HIFU relies on many factors, and it appears highly attractive as a minimally invasive treatment for localized PC as HIFU entails no incision or puncture, it is bloodless, can be carried out on an outpatient basis, and is repeatable.

The clinical outcome of HIFU treatment has improved significantly over the years as a result of technical, imaging, and device improvements. Among these improvements, MR guidance is the most advanced that was lastly 
introduced and has the potential to drive this application for a safer and more effective treatment due to its superior anatomic resolution and its capability to perform real time temperature mapping. Despite initial results on humans where feasibility and safety appear highly promising, MRgFUS is still under investigation, and more studies are needed to demonstrate the oncologic effectiveness as well as to validate its durable effect on patient outcomes.

Disclosure No potential conflicts of interest relevant to this article were reported.

\section{References}

Papers of particular interest, published recently, have been highlighted as:

- Of importance

- Of major importance

1. Siegel R, Naishadham D, Jemal A. Cancer statistics, 2012. CA Cancer J Clin. 2012;62(1):10-29.

2. Singer EA, Kaushal A, Turkbey B, Couvillon A, Pinto PA, Parnes HL. Active surveillance for prostate cancer: past, present and future. Curr Opin Oncol. 2012;24(3):243-50.

3. Heidenreich A, Bellmunt J, Bolla M, Joniau S, Mason M, Matveev V, Mottet N, Schmid HP, van der Kwast T, Wiegel T, et al. EAU guidelines on prostate cancer. Part 1: screening, diagnosis, and treatment of clinically localised disease. Eur Urol. 2011; 59(1):61-71.

4. Singh J, Trabulsi EJ, Gomella LG. Is there an optimal management for localized prostate cancer? Clin Interv Aging. 2010;5: 187-97.

5. Walz J, Burnett AL, Costello AJ, Eastham JA, Graefen M, Guillonneau B, Menon M, Montorsi F, Myers RP, Rocco B, et al. A critical analysis of the current knowledge of surgical anatomy related to optimization of cancer control and preservation of continence and erection in candidates for radical prostatectomy. Eur Urol. 2010;57(2):179-92.

6. - Ahmed HU, Akin O, Coleman JA, Crane S, Emberton M, Goldenberg L, Hricak H, Kattan MW, Kurhanewicz J, Moore CM et al. Transatlantic Consensus Group on active surveillance and focal therapy for prostate cancer. BJU Int. 2012;109(11):1636-47. The changing landscape of prostate cancer epidemiology requires the medical community to re-evaluate the entire prostate cancer diagnostic and treatment pathway.

7. Crouzet S, Poissonnier L, Murat FJ, Pasticier G, Rouviere O, Mege-Lechevallier F, Chapelon JY, Martin X, Gelet A. Outcomes of HIFU for localised prostate cancer using the Ablatherm Integrate Imaging(R) device. Prog Urol. 2011;21(3):191-7.

8. Blana A, Rogenhofer S, Ganzer R, Lunz JC, Schostak M, Wieland WF, Walter B. Eight years' experience with high-intensity focused ultrasonography for treatment of localized prostate cancer. Urology. 2008;72(6):1329-33. discussion 1333-1324.

9. Maestroni U, Dinale F, Minari R, Salsi P, Ziglioli F. Highintensity focused ultrasound for prostate cancer: long-term followup and complications rate. Adv Urol. 2012;2012:960835.

10. Jenne JW, Preusser T, Gunther M. High-intensity focused ultrasound: principles, therapy guidance, simulations and applications. Z Med Phys. 2012;22(4):311-22.
11. Thompson I, Thrasher JB, Aus G, Burnett AL, Canby-Hagino ED, Cookson MS, D'Amico AV, Dmochowski RR, Eton DT, Forman JD, et al. Guideline for the management of clinically localized prostate cancer: 2007 update. J Urol. 2007;177(6): 2106-31.

12. Jolesz FA. MRI-guided focused ultrasound surgery. Annu Rev Med. 2009;60:417-30.

13. Vargas HA, Akin O, Franiel T, Mazaheri Y, Zheng J, Moskowitz C, Udo K, Eastham J, Hricak H. Diffusion-weighted endorectal MR imaging at $3 \mathrm{~T}$ for prostate cancer: tumor detection and assessment of aggressiveness. Radiology. 2011;259(3):775-84.

14. Bonekamp D, Jacobs MA, El-Khouli R, Stoianovici D, Macura KJ. Advancements in MR imaging of the prostate: from diagnosis to interventions. Radiographics. 2011;31(3):677-703.

15. Hoeks CM, Barentsz JO, Hambrock T, Yakar D, Somford DM, Heijmink SW, Scheenen TW, Vos PC, Huisman H, van Oort IM, et al. Prostate cancer: multiparametric MR imaging for detection, localization, and staging. Radiology. 2011;261(1):46-66.

16. Pilatou MC, Stewart EA, Maier SE, Fennessy FM, Hynynen K, Tempany CM, McDannold N. MRI-based thermal dosimetry and diffusion-weighted imaging of MRI-guided focused ultrasound thermal ablation of uterine fibroids. J Magn Reson Imaging. 2009;29(2):404-11.

17. Kirkham AP, Emberton M, Hoh IM, Illing RO, Freeman AA, Allen C. MR imaging of prostate after treatment with highintensity focused ultrasound. Radiology. 2008;246(3):833-44.

18. Quesson B, Laurent C, Maclair G, de Senneville BD, Mougenot C, Ries M, Carteret T, Rullier A, Moonen CT. Real-time volumetric MRI thermometry of focused ultrasound ablation in vivo: a feasibility study in pig liver and kidney. NMR Biomed. 2011;24(2):145-53.

19. Siddiqui K, Chopra R, Vedula S, Sugar L, Haider M, Boyes A, Musquera M, Bronskill M, Klotz L. MRI-guided transurethral ultrasound therapy of the prostate gland using real-time thermal mapping: initial studies. Urology. 2010;76(6):1506-11.

20. Kinsey AM, Diederich CJ, Rieke V, Nau WH, Pauly KB, Bouley D, Sommer G. Transurethral ultrasound applicators with dynamic multi-sector control for prostate thermal therapy: in vivo evaluation under MR guidance. Med Phys. 2008;35(5):2081-93.

21. Cheng CWS KJ, Thng CH, Lau W, Ho H, Khoo JBK. Initial experience with MRg FUS focal therapy for low risk prostate cancer. In: Presented at European Congress of Radiology 2011 Wien, 3-7 Jan 2011 Austria 2011.

22. Napoli A PF, Anzidei M, Catalano C, Passariello R. Noninvasive treatment of prostate and breast cancer: initial clinical experience using high intensity focused ultrasound therapy with 3T magnetic resonance guidance. In: Interventional oncology series: molecular targeting and emerging clinical foci in interventional oncology 2010, Code VO41(RSNA 2010).

23. Borofsky MS, Ito T, Rosenkrantz AB, Taneja SS. Focal therapy for prostate cancer-where are we in 2011? Ther Adv Urol. 2011;3(4):183-92.

24. Tollefson MK, Karnes RJ, Rangel LJ, Bergstralh EJ, Boorjian SA. The impact of clinical stage on prostate cancer survival following radical prostatectomy. J Urol. 2012 (in press).

25. Turpen R, Rosser CJ. Focal therapy for prostate cancer: revolution or evolution? BMC Urol. 2009;9:2.

26. Al-Bataineh O, Jenne J, Huber P. Clinical and future applications of high intensity focused ultrasound in cancer. Cancer Treat Rev. 2012;38(5):346-53.

27. ter Haar G. Ultrasound bioeffects and safety. Proc Inst Mech Eng H. 2010;224(2):363-73.

28. Srigley JR, Delahunt B, Evans AJ. Therapy-associated effects in the prostate gland. Histopathology. 2012;60(1):153-65.

29. Warmuth M, Johansson T, Mad P. Systematic review of the efficacy and safety of high-intensity focussed ultrasound for the 
primary and salvage treatment of prostate cancer. Eur Urol. 2010;58(6):803-15.

30. Blana A, Robertson CN, Brown SC, Chaussy C, Crouzet S, Gelet A, Conti GN, Ganzer R, Pasticier G, Thuroff S, et al. Complete high-intensity focused ultrasound in prostate cancer: outcome from the @-Registry. Prostate Cancer Prostatic Dis. 2012;15(3): 256-9.

31. • Ahmed HU, Hindley RG, Dickinson L, Freeman A, Kirkham AP, Sahu M, Scott R, Allen C, Van der Meulen J, Emberton M. Focal therapy for localised unifocal and multifocal prostate cancer: a prospective development study. Lancet Oncol. 2012;13(6) :622-32. Focal therapy of prostate cancer lesions, whether multifocal or unifocal, leads to a low rate of genitourinary side-effects and an encouraging rate of early absence of clinically significant prostate cancer.

32. Delongchamps NB, Rouanne M, Flam T, Beuvon F, Liberatore M, Zerbib M, Cornud F. Multiparametric magnetic resonance imaging for the detection and localization of prostate cancer: combination of T2-weighted, dynamic contrast-enhanced and diffusion-weighted imaging. BJU Int. 2011;107(9):1411-8.

33. Kim YS, Trillaud H, Rhim H, Lim HK, Mali W, Voogt M, Barkhausen J, Eckey T, Kohler MO, Keserci B, et al. MR thermometry analysis of sonication accuracy and safety margin of volumetric MR imaging-guided high-intensity focused ultrasound ablation of symptomatic uterine fibroids. Radiology. 2012; 265(2):627-37.

34. Yuan J, Mei CS, Panych LP, McDannold NJ, Madore B. Towards fast and accurate temperature mapping with proton resonance frequency-based MR thermometry. Quant Imaging Med Surg. 2012;2(1):21-32.

35. Alongi F, Russo G, Spinelli A, Borasi G, Scorsetti M, Gilardi MC, Messa C. Can magnetic resonance image-guided focused ultrasound surgery replace local oncology treatments? A review. Tumori. 2011;97(3):259-64.

36. Bradley WG Jr. MR-guided focused ultrasound: a potentially disruptive technology. J Am Coll Radiol. 2009;6(7):510-3.

37. Napoli A, Anzidei M, De Nunzio C, Cartocci G, Panebianco V, De Dominicis C, Catalano C, Petrucci F, Leonardo C. Real-time magnetic resonance-guided high-intensity focused ultrasound focal therapy for localised prostate cancer: preliminary experience. Eur Urol. 2012 (in press).

38. Ahmed HU, Cathcart P, McCartan N, Kirkham A, Allen C, Freeman A, Emberton M. Focal salvage therapy for localized prostate cancer recurrence after external beam radiotherapy: a pilot study. Cancer. 2012;118(17):4148-55.

39. Murat FJ, Poissonnier L, Rabilloud M, Belot A, Bouvier R, Rouviere O, Chapelon JY, Gelet A. Mid-term results demonstrate salvage high-intensity focused ultrasound (HIFU) as an effective and acceptably morbid salvage treatment option for locally radiorecurrent prostate cancer. Eur Urol. 2009;55(3):640-7.

40. Uchida T, Shoji S, Nakano M, Hongo S, Nitta M, Usui Y, Nagata Y. High-intensity focused ultrasound as salvage therapy for patients with recurrent prostate cancer after external beam radiation, brachytherapy or proton therapy. BJU Int. 2011;107(3):378-82.

41. Sapareto SA, Dewey WC. Thermal dose detrmination in cancer therapy. Int J Radiat Oncol Biol Phys. 1984;10(6):787-800. 